This PDF is a selection from a published volume from the National Bureau of Economic Research

Volume Title: Labor in the New Economy

Volume Author/Editor: Katharine G. Abraham, James R. Spletzer, and Michael Harper, editors

Volume Publisher: University of Chicago Press

Volume ISBN: 978-0-226-00143-2; 0-226-00143-1

Volume URL: http://www.nber.org/books/abra08-1

Conference Date: November 16-17, 2007

Publication Date: October 2010

Chapter Title: Why Do BLS Hours Series Tell Different Stories About Trends in Hours Worked?

Chapter Author: Harley Frazis, Jay Stewart

Chapter URL: http://www.nber.org/chapters/c10828

Chapter pages in book: (343 - 372) 


\section{Why Do BLS Hours Series Tell \\ Different Stories about Trends in \\ Hours Worked?}

Harley Frazis and Jay Stewart

\subsection{Introduction}

The number of hours that people work for pay is an important economic measure. In its own right, it measures labor utilization. But it is also the denominator of other key economic indicators such as productivity and hourly earnings. Thus, differences in measured hours between surveys can lead to substantial differences in measured productivity and wages. For example, Abraham, Spletzer, and Stewart (1998) show that the different trends in hours measures account for nearly all of the divergence between hourly wages from the National Income and Product Accounts (NIPA), which use hours derived from the establishment-based Current Employment Statistics program (CES), and estimates from the household-based Current Population Survey (CPS). The average hourly wage from the NIPAs grew by 7 percent between 1973 and 1993, while the average hourly wage from the CPS remained roughly constant over that same period. Abraham, Spletzer, and Stewart noted that someone looking at the NIPA data would "have a very different picture of recent real wage trends than someone who looked at the CPS data ..." (295).

Systematic over- or underreporting of hours can affect measured inequality. Frazis and Stewart (2004) found that, compared to time-diary reports, hours of work for women and college graduates tend to be overreported in the CPS. Thus, using weekly hours computed from the American Time Use

Harley Frazis is a research economist in Employment Research and Program Development at the U.S. Bureau of Labor Statistics. Jay Stewart is the Division Chief of the Division of Productivity Research and Program Development at the Bureau of Labor Statistics.

We thank Charlie Brown, Younghwan Song, and the editors of this volume for their helpful comments. Any views expressed here are ours and do not necessarily reflect those of the BLS. 
Survey (ATUS) instead of usual hours from the CPS increases the collegehigh school hourly earnings ratio by 4.1 percentage points and the femalemale hourly earnings ratio by 5.4 percentage points. ${ }^{1}$

The divergence in trends in CPS and CES hours discussed in Abraham, Spletzer, and Stewart (1998) has continued since their paper was published. As the CPS and CES are the two principal sources of data on the subject, both the amount and the trend in how many hours Americans work for pay are in dispute. Figure 9.1 shows trends in average weekly hours of private nonagricultural workers from the CPS and the CES. (We show data from both the March CPS and the CPS Outgoing Rotation Group [ORG] files. The ORG data are more representative, but the March data have a longer time series.) The CPS data indicate that average weekly hours worked declined in the 1960s and early 1970s, increased for most of the 1980s, and leveled off beginning in the late 1980s. The net effect of these changes is that there has been very little change between 1964 and 2007. In contrast, the CES hours series declined between 1964 and the late 1980s, leveled off until the late 1990s, then declined between the late 1990s and 2007.

The main goal of this study is to reconcile the differences between the CPS and CES hours series. Our strategy, which is similar to that used by Abraham, Spletzer, and Stewart (1998, 1999), is to simulate the CES sample using CPS data to show how differences in the two surveys contribute to the divergence in average weekly hours. Specifically, we consider differences in the workers covered, differences in the treatment of multiple jobholders, and differences in the hours concept (hours worked in the CPS versus hours paid in the CES). We also examine whether hours are overreported in the CPS, as has been claimed by some researchers. Finally, we examine whether features of the CES (in particular, changes in the reference period over time), could explain the divergence. We were able to account for most of the difference in levels between the two hours series, but could not explain much of the difference in the trends.

\subsection{Why Might the CES and CPS Hours Series Tell Different Stories?}

There are several reasons why one might expect estimates of hours worked from the two series to differ. First, the CPS data cover all workers, although all comparisons shown here are restricted to private nonagricultural workers. The CES data cover only production (in goods-producing industries) and nonsupervisory workers (in services-providing industries) within the private nonagricultural sector. Nonproduction and supervisory workers are more likely to work full time and generally work longer hours, so that the CPS's inclusion of these workers leads us to expect weekly hours to be higher

1. For a discussion of the importance of hours data for measuring productivity see Eldridge, Manser, and Otto (2004). 


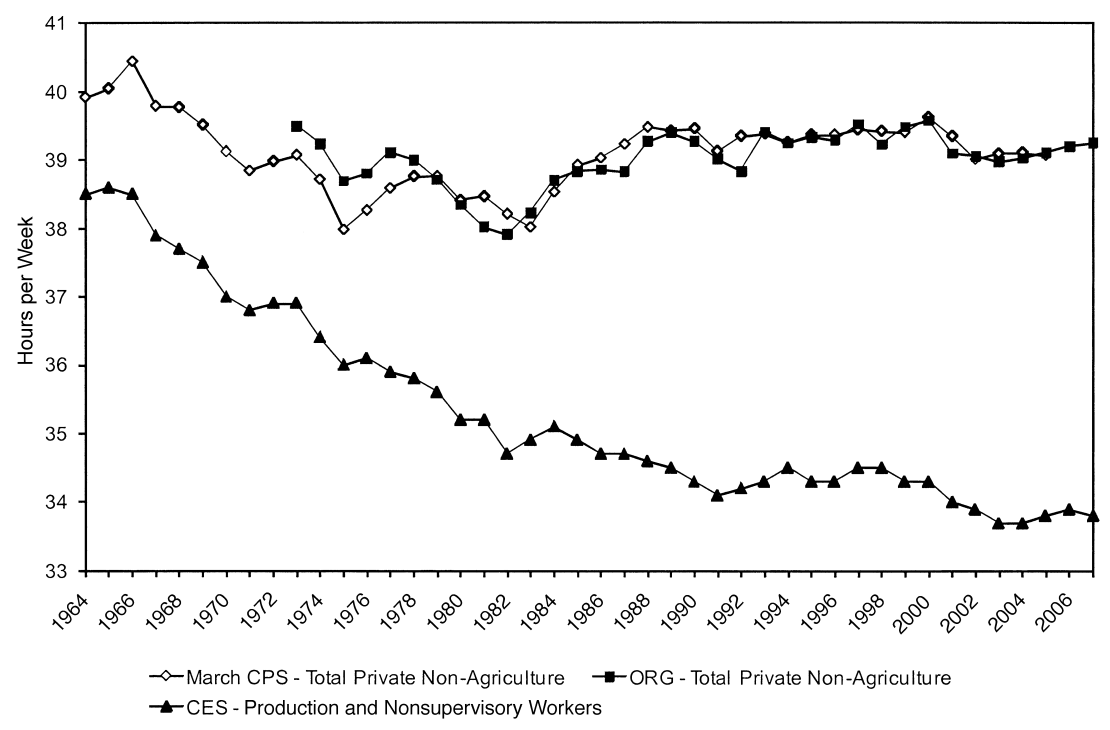

Fig. 9.1 Average weekly hours from CPS and CES data

in the CPS than in the CES. Second, the CES hours series is a job-based measure, whereas the CPS is a person-based measure. Although both series measure total hours worked at all jobs, a person working at two jobs would be counted twice in the CES, but only once in the CPS. Third, the CPS measures hours worked, while the CES measures hours paid. Off-the-clock work would cause the CPS weekly hours series to be higher than the CES series. Fourth, hours may be overreported in the CPS. Some studies (Robinson and Bostrom 1994; Sundstrom 1999) have shown that respondents in household surveys such as the CPS tend to overreport their work hours and that the extent of this overreporting has increased over time. If the CES correctly measures average weekly hours, this story is consistent with the observed relationship between CPS and CES hours. Finally, for reasons we discuss later, the lengthening of pay periods over time could have caused a decline in CES estimates of average weekly hours apart from any real changes in hours. In what follows, we examine each of these possible explanations.

\subsubsection{Differences in Workers Covered}

Differences in workers covered can have a potentially large effect on measured hours if the group that is not covered, nonproduction and supervisory workers, work different hours than the covered group or if the trend in their hours is different. As noted previously, the workers that are excluded from the CES sample work longer hours, which suggests that differences in sample coverage can explain at least some of the difference in levels. It remains to be seen if this difference can explain the difference in trends. 
To examine the effect of differences in coverage, it is necessary to make the two samples comparable. Because the CES has not typically collected hours information on nonproduction and supervisory workers, it is impossible to adjust the CES series to be comparable to the CPS series. So we use the same strategy as Abraham, Spletzer, and Stewart $(1998,1999)$ and simulate the CES sample using CPS ORG data for 1979 to 2007 and May Supplement data for 1973 to $1978 .^{2}$

We restricted the sample to individuals age fifteen and older who worked during the CPS reference week and were identified as being either production (in goods-producing industries) or nonsupervisory (in services-providing industries) workers using the CPS industry and occupation codes. The distinction between production and nonsupervisory workers is important. Occupations that are classified as nonsupervisory are not necessarily classified as production workers. For example, accountants and attorneys are nonsupervisory workers in service-providing industries, but they are not production workers in goods-producing industries.

It is fairly straightforward to distinguish between goods-producing and services-providing industries in most cases. ${ }^{3}$ The classification of workers as production and nonsupervisory workers in their respective sectors was somewhat problematic. The instructions to respondents on the CES forms are fairly detailed regarding which types of workers should be counted as production and nonsupervisory workers. Because the definition of covered workers depends on the industry, we used both industry and occupation codes to classify workers as being covered by CES. Unfortunately, the detailed (three-digit) Census occupation codes used in the CPS do not exactly coincide with the CES instructions, and there were two major changes in the Census occupation codes during the 1973-to-2007 period covered by our simulations (between 1982 and 1983 and between 2002 and 2003).

Figure 9.2 shows the simulated CES average weekly hours series, along with the actual CES hours and CPS ORG private nonagricultural worker (PNAW) series. The first thing to note is that the simulated CES hours series is closer in level to the actual CES series than the CPS PNAW series. Hours per week are between 1.3 and 1.7 hours less in the simulated CES series compared to the CPS PNAW series. However, the simulated CES series exhibits the same roughly flat trend as the CPS PNAW series and does not replicate the downward trend in the actual CES series.

One possible explanation for the lack of a downward trend in the simu-

2. We did not simulate the CES hours series using the March data, because it does not have any information on second jobs or hourly/salaried status. Following Abraham, Spletzer, and Stewart (1998, 1999), we assume that the May Supplements are comparable to the ORG data.

3. There was a break in series between 2002 and 2003 when the new Census industry codes were introduced. This change likely resulted in a more accurate coding of workers, but workers who were previously coded as being in manufacturing are now classified as being in business services. 


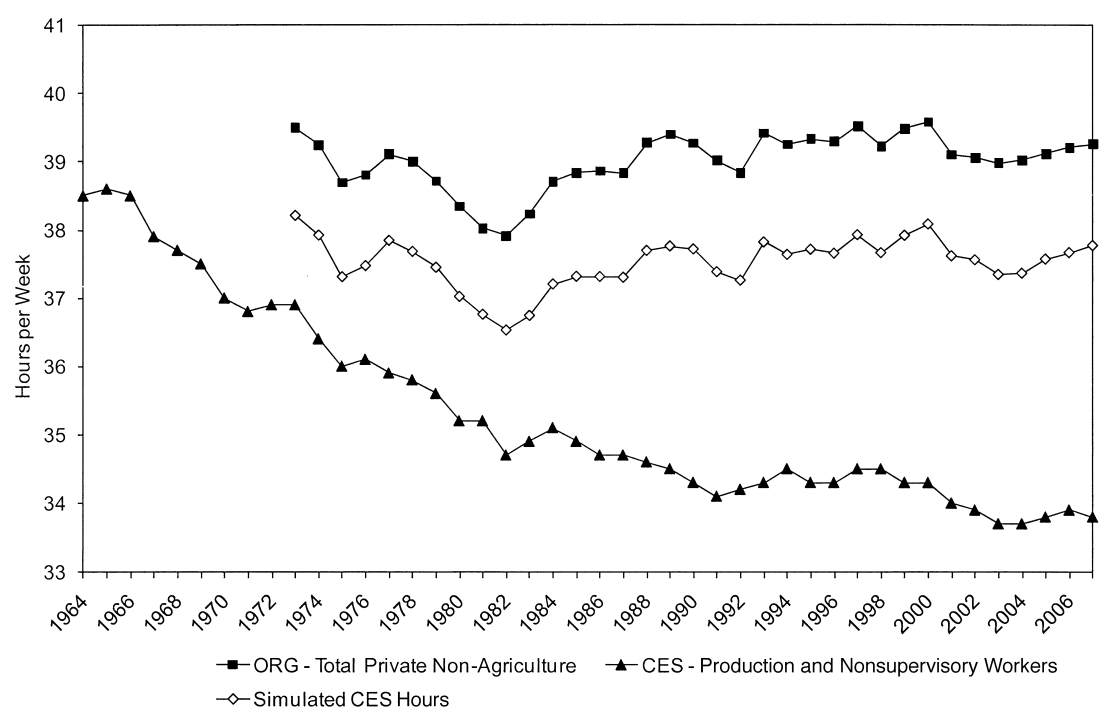

Fig. 9.2 Comparison of CES weekly hours to CPS replications of CES weekly hours not adjusted for multiple jobholding

lated CES series is that employers may not always classify workers according to the instructions on the form. This can occur for a number of reasons. First, respondents may not read the instructions on the form and instead use their own definitions, which may not correspond to the Bureau of Labor Statistics'(BLS). Second, respondents' recordkeeping systems may not allow workers to be classified using the BLS definitions. For example, the distinction between supervisory and nonsupervisory workers (in services) may not be meaningful. A more meaningful distinction may be whether workers are covered by minimum wage/overtime laws. Findings from the BLS's internal Records Analysis Survey (RAS) studies indicate that a large number of establishments reported for workers who are not exempt from minimum wage laws. However, it does appear that the production/nonproduction worker distinction (in goods-producing industries) is meaningful and that respondents are for the most part reporting for the correct group of workers.

To examine whether employers in service-providing industries could be using the exempt/nonexempt distinction, we constructed an alternative "hybrid" simulated CES series. For production workers the hybrid series uses the CES definition, while for nonsupervisory workers we attempted to identify workers who, based on their occupation and whether they were paid hourly, were likely to be nonexempt from wage/hour laws. ${ }^{4}$ This hybrid series

4. The CPS does not contain information on whether a worker is exempt or not, so we used information on the worker's detailed occupation and whether he or she was paid hourly. We 
was similar to the one we report, except that the 1982 to 1983 change in occupation codes caused a break in series that resulted in a onetime downward shift in the simulated hours series. Because this break in series strengthens our results by narrowing the difference between the two surveys, we took the conservative approach and used the CES definitions for both industries.

\subsubsection{Accounting for Multiple Jobholding}

As noted earlier, the CES measure is job-based whereas the CPS measure is person-based. The two measures would be the same if each person held only one job, but about 5 to 6 percent of the population has more than one job at any one time. To account for multiple jobholding, we reran the simulations, counting each job separately. ${ }^{5}$ Since 1994 , information on multiple jobholding has been collected every month, while prior to 1994, this information was collected only in the May supplements to the CPS from 1973 to 1978, 1985, and 1991. We combine these May supplement data with the ORG data for 1994 to 2007, but acknowledge that there may be some seasonal variation in the multiple jobholding rate.

Figure 9.3 shows the multiple-jobholding-adjusted (MJA) simulated CES hours series. In the years when no information on multiple jobholding is available (1979 to 1984, 1986 to 1990, and 1992 to 1993), hours for the MJA series are set equal to simulated CES hours (from figure 9.2) divided by interpolated values of the implied multiple jobholding rate. ${ }^{6}$ As expected, the multiple jobholding adjustment reduces estimated hours worked compared to the unadjusted simulated CES series (also shown in figure 9.3). The MJA series is about 1.6 hours per week lower than the simulated CES series, although the difference varies between 1.1 and 2.0 hours per week with no discernable trend. The MJA series further narrows the difference in levels between CES and CPS hours, but still does not replicate the downward trend in actual CES hours.

There is virtually no difference between the MJA series and the actual CES

assumed that all hourly paid workers were nonexempt. The remaining workers were classified as exempt if they were supervisors or if their jobs allowed them considerable autonomy as outlined in the minimum wage law. This classification is rather crude. Determining whether a worker is exempt from minimum wage laws is complicated by the fact that exempt status depends on a number of variables that are not available in the CPS. For example, workers in "mom-and-pop" businesses are generally exempt. Another complicating factor is that the law has changed over time. We could not account for these changes in the CPS data, but the reader should keep this in mind.

5. A small fraction, about 5 percent, of multiple jobholders hold more than two jobs. We experimented with making a further adjustment, similar to our initial multiple-jobholding adjustment, to account for these third jobs, but it made virtually no difference.

6 . In the years for which we have data, we computed the implied multiple jobholding rate by dividing the simulated CES hours series by the MJA series. The implied multiple jobholding rate ranged from 3.1 percent to 5.6 percent. This differs from the published multiple jobholding rate, because some people with CES-covered main jobs have second jobs that are not covered, and vice versa. The between-supplement values of the implied multiple jobholding rate were linearly interpolated using values from the adjacent supplement years. 


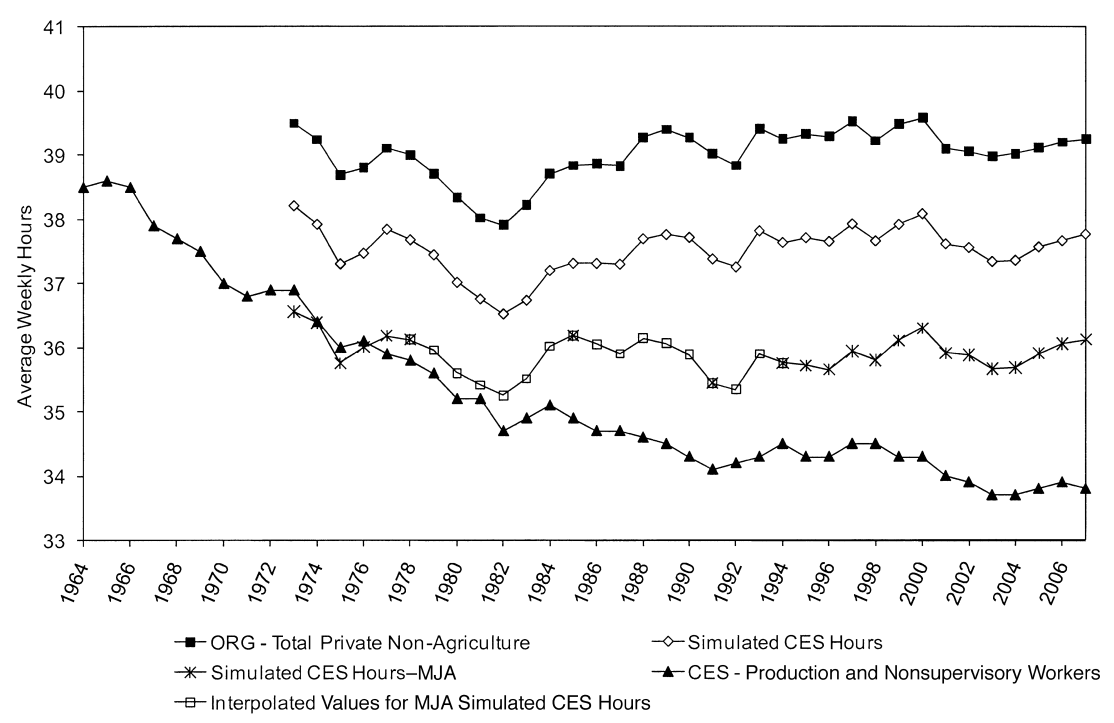

Fig. 9.3 Comparison of CES weekly hours to CPS replications of CES weekly hours adjusted for multiple jobholding

series between 1973 and the early 1980s. Over this period, both series exhibit a downward trend and turn up immediately after the 1982 recession. The fall in hours between 1982 and 1983 is larger in the actual CES series compared to the MJA series, which could be at least partially due to the change in CPS industry and occupation codes between these years.

After 1983, the MJA series behaved very differently from the actual CES series. The increase in hours between 1983 and 1984 was larger than the increase in the actual CES. And from 1984 through the rest of the 1980s it remained approximately flat, while the actual CES series declined. Beginning in 1990, apart from the higher level, the MJA series tracks the actual CES series fairly well until the late-1990s, when the CES and CPS replications diverge further. Between 1998 and 2007, the difference increased from 1.3 hours per week to 2.3 hours per week. This coincides with the conversion of the CES to a probability sample and the introduction of North American Industry Classification System (NAICS) codes. It seems unlikely that the introduction of NAICS codes could have affected the trend in hours. But the conversion to a probability sample presumably changed the sample composition, which could have led to a decline in hours.

\subsubsection{Hours Paid versus Hours Worked}

As noted earlier, the two series differ in the hours concept being measured. The CPS measures hours worked, while the CES measures hours paid. The usual way to account for the difference between these two concepts is to 
adjust the CES hours data for paid vacations. ${ }^{7}$ Because this adjustment does not account for off-the-clock work, we opted for a different approach and instead adjusted the CPS data.

We began by assuming that hourly paid workers are paid for all of the hours that they work - so that no adjustment was necessary — and that salaried workers are paid for a standard workweek. The CPS does not have any information on hourly/salaried status for second jobs, so we assumed that multiple jobholders are paid hourly on their second jobs. Given that second jobs are almost always part-time, this seems like a reasonable assumption and should not affect the results. For individuals who are salaried on their main job, we assumed that they are paid for a forty hour workweek. Thus, we set hours paid at forty if they worked more than forty hours on their main job, or if they worked less than thirty-five hours but indicated that they usually work full time. To account for paid time off, we included individuals who were employed and did not work during the CPS reference week if they were paid for that time off. We assumed that they were paid for their usual hours on their main job (topcoded at forty if salaried).

It was necessary to impute hourly/salaried status for some observations. In the 1973 to 1978 and 1994 to 2007 data, hourly/salaried status is missing due to nonresponse for about 2 percent of the sample. In the 1985 and 1991 May Supplements, hourly/salaried status was collected only of individuals in (months-in-sample) MIS 4 and 8, and was therefore missing for threefourths of the sample. To fill in the missing values, we used a logit equation to estimate the probability that an individual was paid hourly based on demographic and job characteristics, and then assigned individuals their predicted probabilities when hourly/salaried status was missing. For observations with imputed hourly/salaried status, the hours-paid adjustment was proportional to the probability that the individual was paid hourly. For example, an individual who worked forty-eight hours and had a 0.25 predicted probability of being paid hourly would be assigned a workweek of forty-two hours.

Figure 9.4 shows the effect of this adjustment. The multiple-jobholding and hours-paid adjusted (MJ \& HPA) series is lower in level compared to the MJA series, but their trends are identical. Note also that the MJ \& HPA series lies below the actual CES series prior to 1984. Other authors (Kuhn and Lozano 2008) have documented the increase in long workweeks. But it appears that any increase in off-the-clock work has not had a large impact on trends in average hours worked.

\subsubsection{Possible Overreporting of Hours Worked in the CPS}

The conventional wisdom among researchers who analyze time-use data is that respondents in household surveys such as the CPS tend to overreport

7. The BLS used to conduct a special survey, the Survey of Hours Worked, to determine what fraction of paid hours is actually worked. The fraction is about 0.93 and shows very little year-to-year variation. The survey was discontinued in 2003 and these data are now collected through the National Compensation Survey. Sundstrom (1999) makes this adjustment. 


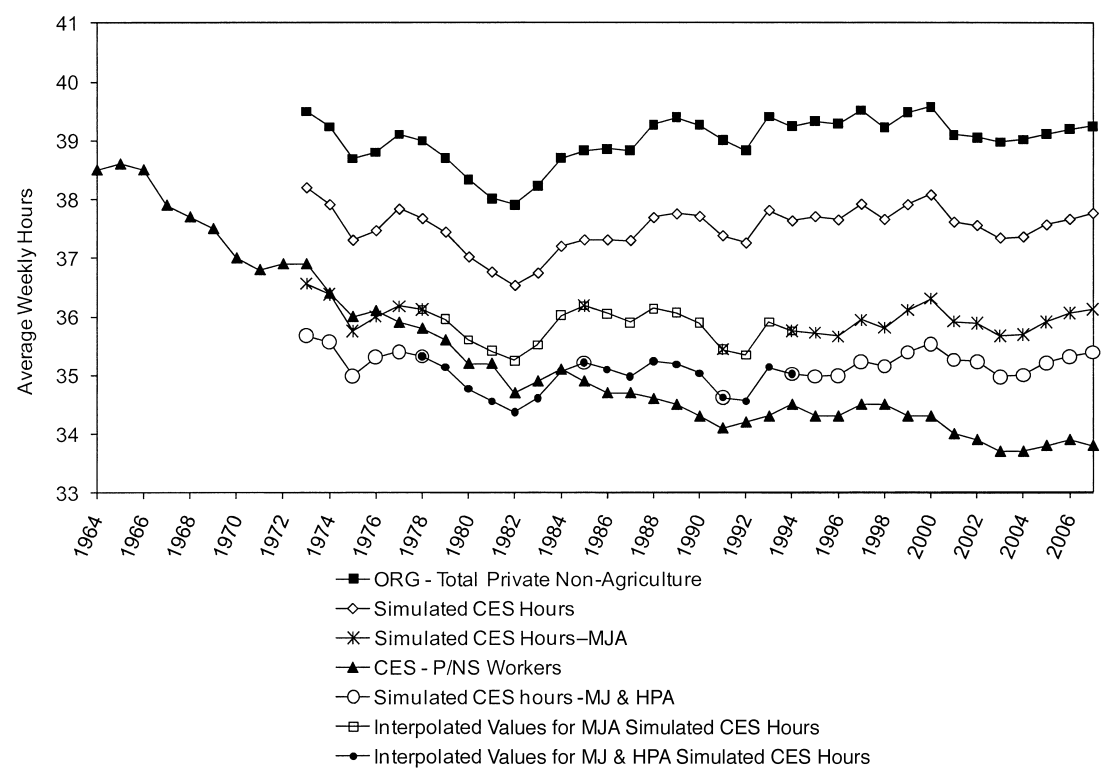

Fig. 9.4 Comparison of CES weekly hours to CPS replications of CES weekly hours adjusted for multiple jobholding and paid time off

their work hours. If this is the case and if the extent of overreporting has increased over time, as some researchers have found, this could explain the divergence of CPS and CES hours.

Research on this issue has taken one of two approaches: comparing reports from household surveys to reports for the same individuals from their employers (Mellow and Sider 1983; Rodgers, Brown, and Duncan 1993); or comparing household survey responses to time-diary data (Robinson 1985; Robinson and Bostrom 1994; Sundstrom 1999; Williams 2004; Frazis and Stewart 2004, 2007). Mellow and Sider found that workers overreported hours compared to their employers' records, and that salaried workers overreported the most. ${ }^{8}$ In contrast, Rodgers, Brown, and Duncan found no evidence of overreporting, but their sample was restricted to hourly paid workers at a large unionized firm. The earlier studies that used time-diary data (Robinson 1984; Robinson and Bostrom 1994; Sundstrom 1999) found evidence of overreporting in household surveys. The Robinson and Bostrom study found that the extent of overreporting increased from about one hour per week in 1965 to about six hours per week in 1985. Their findings, if correct, could explain the divergent trends in CES and CPS hours as well as the difference in levels. However, more recent studies (Williams 2004; Frazis

8. Regarding the latter point, it is worth noting that employers likely reported hours paid while employees reported hours worked. These differing reports are consistent with employees "working off the clock." 
and Stewart 2004, 2007) found evidence that household surveys correctly reported, or even underreported, hours. All of these studies found that some groups overreport hours, while others underreport.

There are several reasons why time-diary data might be preferable to data from household surveys that ask respondents to report about hours worked in the previous week. The recall task is generally easier in a time-use survey. The reference period is the previous day so that respondents need not try to recall over longer periods, and because they are reporting individual episodes of work they do not have to add the lengths of different episodes. Paid work that occurs at home or other locations, which respondents may not report when responding to retrospective questions, is counted in time-diary estimates. Time diaries also have an adding-up constraint that forces the sum of time spent in all activities to equal twenty-four hours.

In this section we use data from the American Time Use Survey (ATUS) to examine the accuracy of CPS hours reporting on CES jobs. Our main purpose is to see if differences in the reporting of hours over time can account for the divergence between the CPS and CES series. Sample sizes for previous time-use surveys are too small to allow us to do this directly (not to mention issues with comparability). However, we can use demographic and job characteristics associated with under- or overreporting of hours in CPS relative to the 2003 to 2006 ATUS and estimate the trend in reporting implied by changes in the characteristics of the employed.

The ATUS sample is a stratified random sample that is drawn from households that have completed their eighth and final month-in-sample in the CPS $^{9}$ (hereafter MIS 8) and is designed to be representative of the U.S. civilian population. Interviews were conducted by telephone every day during the year except for a few major holidays. ${ }^{10}$ Thus, the data cover the entire year, except for the days before these holidays. ${ }^{11}$

As in other time-use surveys, respondents are asked to sequentially report their activities on the previous day. The diary day starts at 4:00 a.m. and goes through 4:00 a.m. of the following day (the interview day), so that each interview covers a twenty-four-hour period. After the core time diary has been completed, the ATUS asks respondents whether any activities that were not identified as paid work were done as part of their job or business. This question improves identification of paid work activities for self-employed respondents who work at home and others who do not "go to work" in the traditional sense.

9. Households are in the CPS sample for four months, out for eight, and then in for another four.

10. Reference days before major holidays are missed, as the telephone centers are closed. The remaining days in the month that fall on the same day of the week as the missing day have their weights inflated to make up for the missing day, in effect making the assumption (which we make in the absence of other information) that the activities on the missing day are similar to those on other days with the same day of the week.

11. For details about the ATUS, see Frazis and Stewart (2007) and Hamermesh, Frazis, and Stewart (2005). 
We can also identify breaks, which allows us to determine how sensitive our results are to alternative definitions of paid work. ${ }^{12}$ Given these advantages, we will proceed under the assumption that the time-diary estimates are correct.

The ATUS also contains labor force information about the respondent that was collected using a slightly modified version of the monthly CPS questionnaire. These questions allow us to determine whether the respondent is employed, unemployed, or not in the labor force (NILF). One notable difference between ATUS and CPS employment questions is that the ATUS reference period is the seven days prior to the interview - the last day being the diary day-instead of the previous calendar week as in the CPS. For respondents who are employed, the ATUS asks about usual hours worked, but does not collect actual hours worked during the previous week. ${ }^{13}$

For this study, we pooled data from 2003 through 2006. We restricted our sample to respondents fifteen years and older who worked at a job during the seven days prior to their ATUS interview. The combined sample size from 2003 to 2006 was $37,035 .{ }^{14}$ Our previous work used only 2003 data.

One drawback of using time-diary data is that the reference period is only one day. Previous researchers (e.g., Robinson and Bostrom 1994) constructed synthetic workweeks by generating estimates for each day of the week and adding up the estimates. Our approach is equivalent. ${ }^{15}$ Thus, we can compare means for specific demographic groups, but we cannot compare the distributions of hours worked between the two surveys.

As noted previously, the detailed information in the ATUS allows us to consider alternative definitions of paid work. We calculate three different measures of hours worked, each of which corresponds to a different concept. Going from the most restrictive measure to the least restrictive, these are:

12. Hamermesh (1990) is one attempt we have seen to examine the effect of paid breaks on wages. Interviewers prompt respondents by asking, "Did you take any breaks of fifteen minutes or longer?" whenever a work episode is reported. Beginning in 2004, this prompt was incorporated into the instrument. The prompt automatically pops up whenever work episodes of four hours or longer are reported.

13. Even if it were available, there is a potential problem with using estimates of actual hours worked for the previous week, because the procedure used for contacting respondents in ATUS could impart bias into estimates of actual hours for the previous seven days. Each designated person is assigned an initial calling day. If he or she is not contacted on that day, the interviewer makes the next call one week later, thus preserving the assigned day of the week. Individuals who are unusually busy during a particular week (perhaps because they worked long hours) are less likely to be contacted during that week, making it more likely that they are contacted the following week (and asked to report hours for the busy week). Hence, long work weeks would tend to be oversampled, resulting in a correlation between hours worked during the previous week and the probability that that week is sampled.

14. The response rate for the ATUS varies from about 55 percent to 58 percent. It is also worth noting that interviews with fewer than five episodes or more than three hours of uncodeable activities are not included in the ATUS public-use file.

15. For basic comparisons, we reweight observations so that all days of the week receive equal weight. When computing regressions, we generate separate estimates for weekdays and weekends and take a weighted average of the two estimates. 
1. Time spent in activities coded as "Working at job."

2. Definition (1) plus activities identified as breaks and time spent in work-related travel (not commuting). ${ }^{16}$

3. Definition (2) plus activities that were coded as being done for the respondent's job (for example, taking a client out to dinner).

We believe that definition (2) is the most appropriate for comparison, because it is likely that individuals include paid breaks and work-related travel when reporting hours. Including these activities adds about 0.4 hours per week. The ATUS does not determine whether work-related activities were done for the main job or for second jobs, so we assumed that all workrelated activities were done for the main job. Thus definitions (2) and (3) are the same for second jobs. These activities may or may not be included in CPS hours reports, but in practice, there is very little difference between definitions (3) and (2) for the main job (0.1 hour per week).

Because CES is job-based, we examine differences in hours per job between CPS and ATUS. (This differs from the person-based analysis in Frazis and Stewart [2004, 2007]). As previously stated, we simulate the CES sample in ATUS as we did in the CPS. For main jobs, this is straightforward, as the information available is identical to CPS. For second jobs, ATUS does not contain information on class of worker, industry, or occupation. We assign CES status to second jobs in ATUS as follows. If the ATUS respondent had a second job in both their last month in CPS and in ATUS, we use their second-job CES status in CPS. If the ATUS respondent had a second job in ATUS but not in CPS, we weight that job by the predicted probability of its being a CES job. The predicted probabilities come from a logit regression of CES status for CPS second jobs in their last month in CPS. ${ }^{17}$ Because these multiple jobholders did not have second jobs approximately three months prior to their ATUS interview, we restricted the sample for this regression to CPS respondents who did not have a second job three months earlier. ${ }^{18}$

Table 9.1 compares estimates of hours worked from the ATUS (in the first three columns) to estimates from the CPS (in the fourth column) for the 2003 to 2006 period. The top six rows show average weekly hours averaged over all jobs, for main jobs, and for second jobs; and the difference between ATUS and CPS estimates. ${ }^{19}$ Averaging over all jobs, the difference between CPS and ATUS estimates of hours worked varies between -2.4 and -2.9 hours per week, depending on the ATUS definition of work, with negative values

16. The inclusion of breaks is justified on the grounds that breaks can be productive (see Hamermesh 1990). Work-related travel is defined as travel between same-job work sites, and we identified travel spells as work-related by looking at the surrounding activities.

17. The covariates are female, age and age squared, CES status of the first job, usual hours on first and second jobs, and dummies for "usual hours vary" on first and second jobs.

18. That is, the sample is individuals who were multiple jobholders in MIS 8 , but held only one job in MIS 5.

19. We performed a similar analysis on a per-person basis. The results are similar, and virtually identical to those in Frazis and Stewart (2007), which used only 2003 data. 


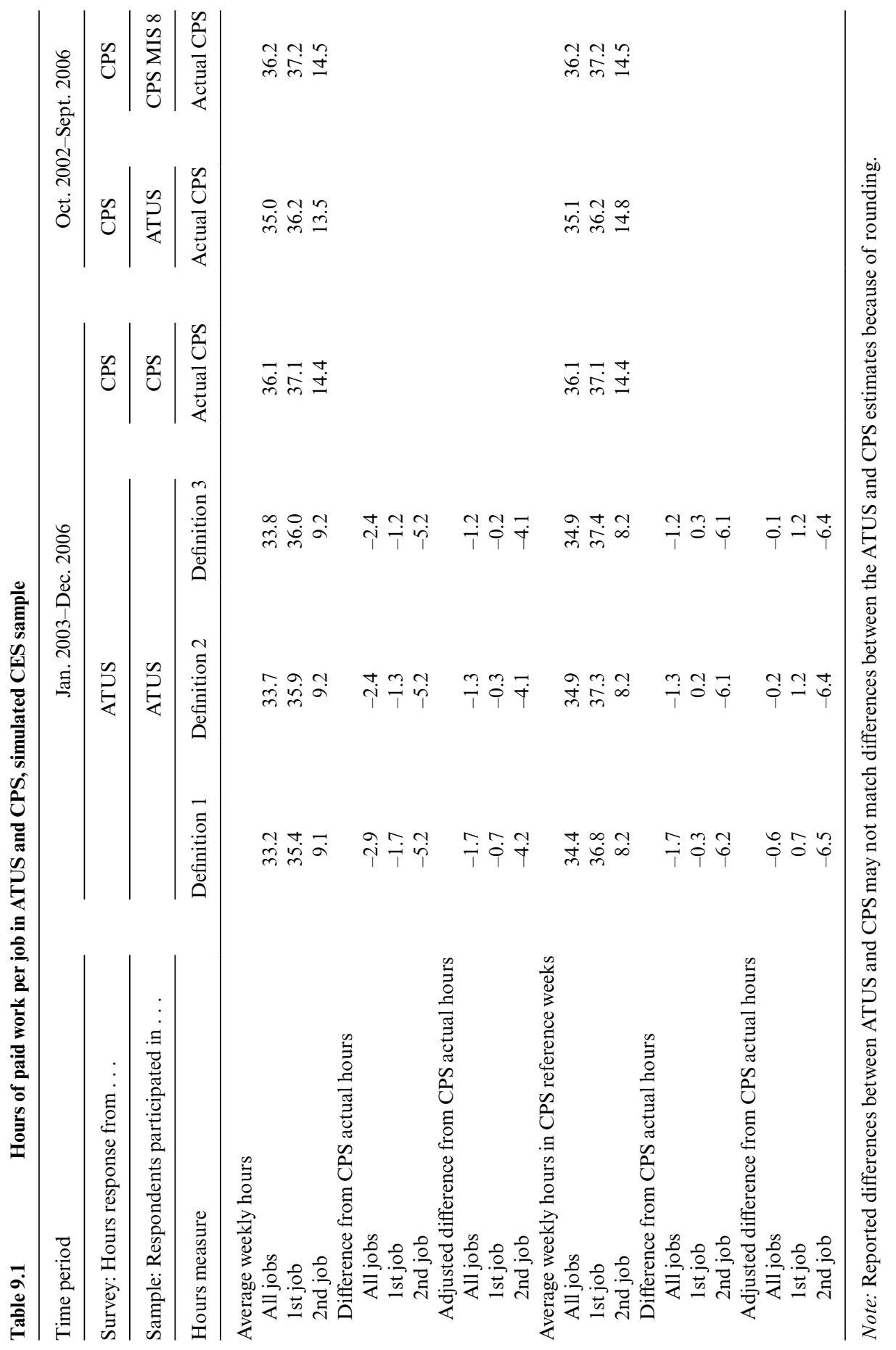


indicating overreporting in CPS. The difference between CPS and ATUS is -5.2 hours per week for second jobs, which is considerably larger than the range of -1.2 to -1.7 hours for main jobs.

Because our interest is in whether CPS responders overreport hours, it is necessary to minimize the effect of any differences in sample composition between the ATUS and the CPS. By using sample weights, we control for any observed differences in sample composition between the two surveys. However, the ATUS response rate is sufficiently low-an average of 57 percent over the 2003 to 2006 period - that there may be unobserved differences between ATUS responders and the broader population of CPS responders that are correlated with hours worked. As we noted earlier, households that have completed their final (MIS 8) CPS interview are used as the sampling frame for the ATUS. This means that we can use CPS data to compare the subset who responded to the ATUS to the entire CPS sample. Specifically, we compare reports of actual hours worked from the CPS MIS 8 interview for ATUS sample members to reports for all individuals in the CPS MIS 8 sample. Because the ATUS interview occurs about three months after the CPS MIS 8 interview, we made this comparison for the period covering October 2002 through September 2006. ${ }^{20}$ These estimates are shown in the last two columns of table 9.1. We use the difference between these two sets of estimates to adjust our earlier estimates. Thus, the sample-selection-adjusted difference between CPS and ATUS hours reports is given by:

$$
\begin{aligned}
D= & E\left(H_{i, t}^{A T U S}\right)-E\left(H_{i, t}^{C P S}\right) \\
& -\left[E\left(H_{i, t-3, M I S 8}^{C P S} \mid i \text { in ATUS }\right)-E\left(H_{i, t-3, M I S 8}^{C P S}\right)\right],
\end{aligned}
$$

where $i$ denotes individual, the second subscript denotes the time period in months, and the third subscript (when present) denotes month-in-sample. Note that because the adjustments are based on reported hours in CPS, they are independent of the ATUS definition of hours.

The sample-composition effects are 1.2 hours per week when averaged over all jobs and 1.0 hour per week for both main and second jobs. This yields adjusted differences of between -1.7 and -1.2 hours per week for all jobs, between -0.7 and -0.2 for main jobs, and between -4.2 and -4.1 for second jobs. Thus, accounting for differences in sample composition reduces our estimates of overreporting in CPS.

As noted in Frazis and Stewart $(2004,2007)$, the reference periods in the CPS and ATUS cover different portions of the calendar. The reference periods for the ATUS include almost every day in the calendar, while the CPS reference week is virtually always the week of the 12 th. ${ }^{21}$ This week was

20. The ATUS interview usually occurs between two and four months after the CPS MIS 8 interview.

21. For some Decembers, reference week is the week of the 5 th to avoid conflicts of the fielding period with Christmas. 
chosen to avoid holidays, so there might be a systematic difference between reference and nonreference weeks. We now control for differences in reference periods by restricting the ATUS sample to CPS reference weeks. The results are shown in the lower panel of table 9.1. The difference between ATUS and CPS hours estimates changes dramatically, with gross differences over all jobs falling by about 1.2 hours per week for each of the three ATUS measures. After adjusting for sample composition, the differences fall by another 1.1 hours per week. These adjusted differences range between -0.6 and -0.1 hours per week and are neither economically nor statistically significant. ${ }^{22}$ Thus, as in our earlier work, we find that the original difference of over two hours is completely explained by sample composition and the difference between reference and nonreference weeks in CPS.

This close correspondence between ATUS and CPS estimates of average hours per job is the sum of three effects, one of which works in the opposite direction from the other two. First, hours on main jobs are underreported for reference weeks by 0.7 to 1.2 hours, significant at the 5 percent level for definitions (2) and (3). Second, hours on second jobs are overreported for reference weeks by 6.5 to 6.4 hours, significant at the 1 percent level. And third, the proportion of second jobs is higher in ATUS by 3.3 percentage points after adjusting for sample composition. This high proportion of second jobs reported in ATUS relative to that reported in CPS by ATUS sample members reduces relative ATUS hours per job by a full hour.

It is important to emphasize that our result - that CPS respondents underreport hours on main jobs - applies only to the simulated CES sample. When we also include non-CES jobs, the estimated difference in hours on the main job during CPS reference week adjusted for sample composition is only -0.3 to 0.2 hours and is not statistically significant. Differences between CPS and ATUS in second-job-hours reporting and the proportion of second jobs are similar between the simulated CES sample and the larger sample. Thus, over both CES and non-CES jobs the implied difference between CPS and ATUS is -1.7 to -1.2 hours per job, which is mostly due to the higher proportion of second jobs in ATUS.

How do these differences vary across subpopulations? Table 9.2 shows a number of comparisons for the simulated CES sample for hours worked during CPS reference weeks. Underreporting appears to decrease with education, although only college graduates show a statistically significant degree of overreporting. This result matches Frazis and Stewart (2004), who used a sample of individuals who were employed at the time of both their CPS and ATUS interviews and whose reported usual hours had not changed much. Unlike Frazis and Stewart (2004), table 9.2 shows no evidence that women's

22. The ATUS standard errors are computed using replicate weights that account for survey design effects (BLS 2009). In computing the standard error of CPS-ATUS differences, the variance in CPS statistics is ignored. 


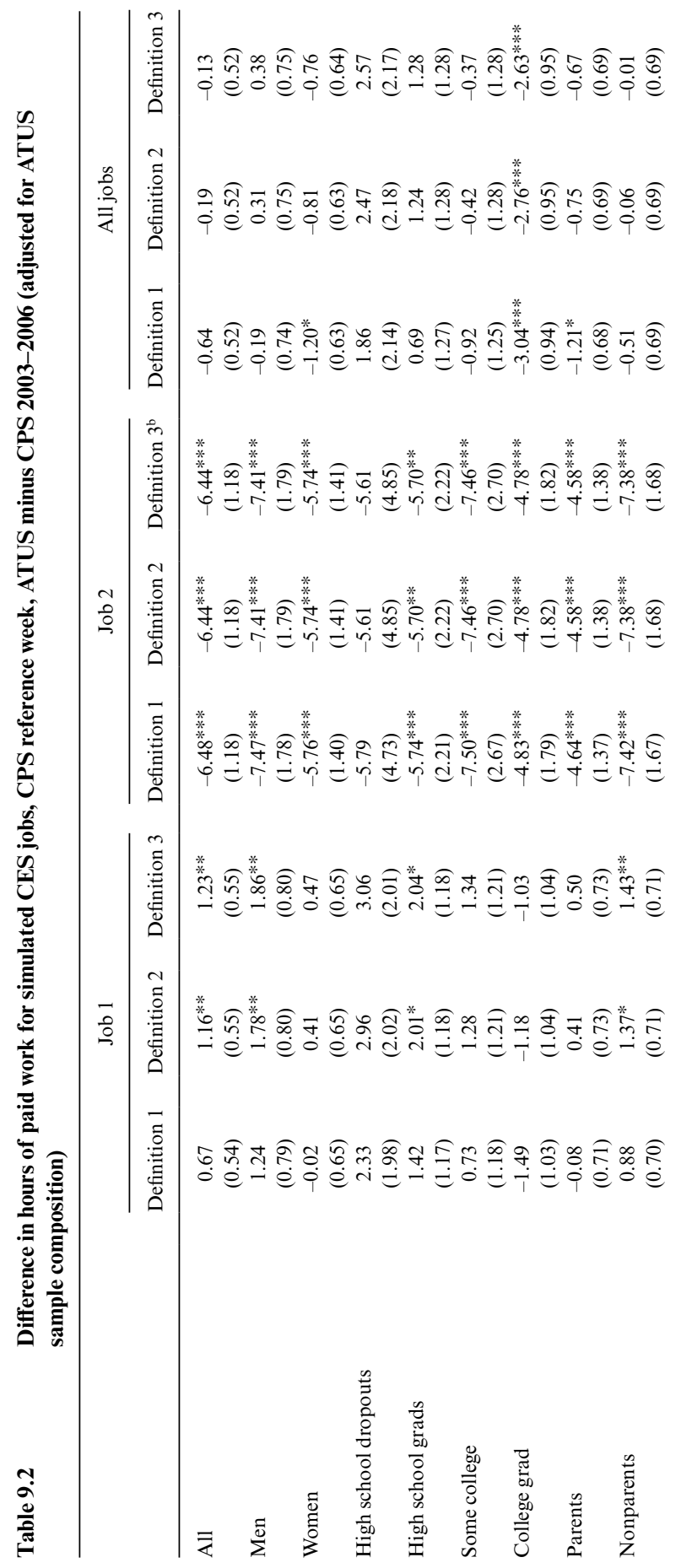




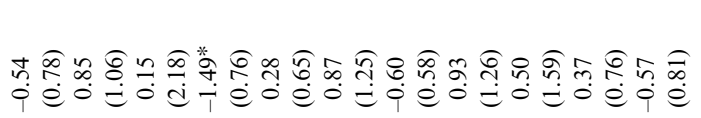

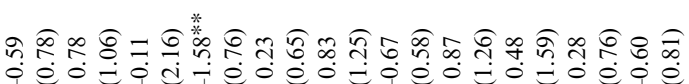

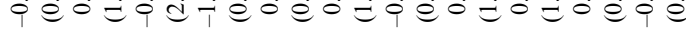

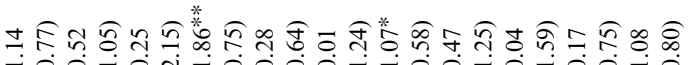
†

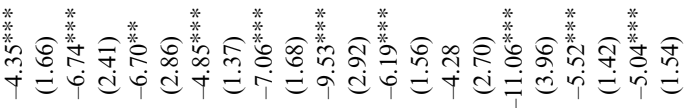

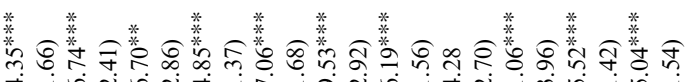

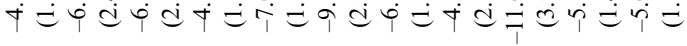

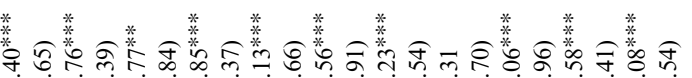

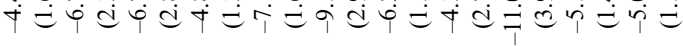

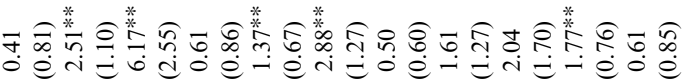

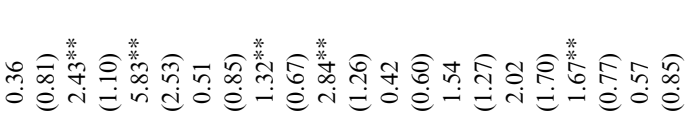
กำ

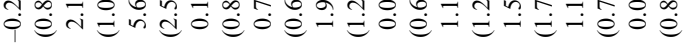

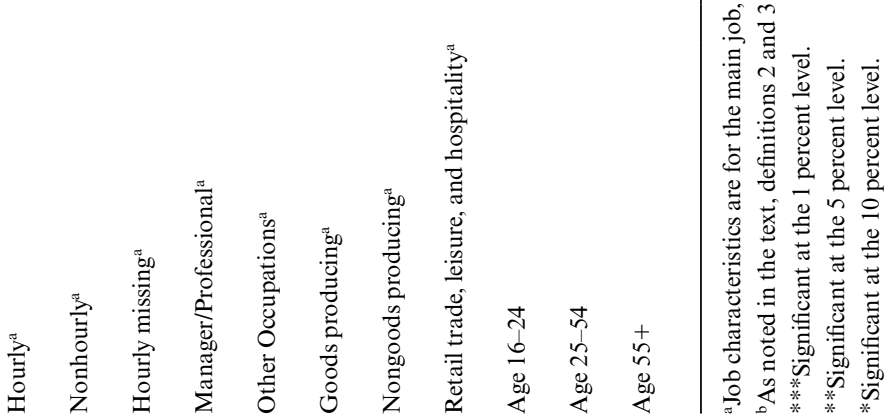


hours are overreported. Other comparisons in table 9.2-by age, parental status, hourly pay, occupation, and industry - are new. Most fail to show significant differences between ATUS and CPS samples.

It is important to note that the differences in table 9.2 are simple averages and do not account for possible correlations between the variables. We can control for these correlations by conditioning the terms in equation (1) on a vector of covariates. Rewriting equation (1) so that each term is replaced by the predicted value from the appropriately defined regression and arranging terms, one can estimate:

$$
\begin{aligned}
D(X) & =\left(X \beta^{A T U S}-X \beta^{C P S}\right)-\left(X \beta_{t-3, M I S 8, A T U S}^{C P S}-X \beta_{t-3, M I S 8}^{C P S}\right) \\
& =X\left[\beta^{A T U S}-\beta^{C P S}-\left(\beta_{t-3, M I S 8, A T U S}^{C P S}-\beta_{t-3, M I S 8}^{C P S}\right)\right],
\end{aligned}
$$

where the $\beta$ s are vectors of regression coefficients corresponding to the samples denoted in the sub- and superscripts. Because the samples corresponding to each $\beta$ differ, we ran separate regressions for each component and generate predicted values for differences between ATUS and CPS using equation (2). This allows us to see if some of the results in table 9.2 are due to correlations with other variables. It also allows us to "backcast" differences between ATUS and CPS in different years, using regression coefficients to obtain average predicted values of the difference in reported hours.

We restricted the ATUS sample to CPS reference weeks, and estimated equation (2) for all three definitions of work. The coefficients are reported in table 9.3. Looking at the reference week results, some differ from table 9.2. There is now stronger evidence that women overreport hours relative to men and parents relative to nonparents. Age has a significant effect, with hours reported in CPS relative to ATUS peaking at age thirty-eight in our quadratic specification. To examine whether reporting could have changed over time, we backcast reporting error using data from the 1984 to 2007 CPS and the coefficients from table 9.3 for all jobs using ATUS definition (2). We generated predicted values for each individual in the simulated CES sample and computed the weighted mean for each year. The backcasts in figure 9.5 show the amount by which average weekly hours are over- or underreported for workers whose main jobs are in the CES sample. Changes in over- or underreporting come about through compositional changes among people in CES-covered jobs. As before, negative values indicate overreporting.

Figure 9.5 indicates that CPS reporting has not changed much over time. The backcast shows that, consistent with our findings in table 9.2, on average CPS respondents reported hours correctly between 2003 and 2006, and that underreporting was greater going back in time. In 1984, CPS respondents underreported hours by about 0.4 of an hour per week, so that there has been a trend toward decreased underreporting. This trend works to increase the CES-CPS divergence. Thus, it works in the same direction as Robinson and 


\begin{tabular}{|c|c|c|c|c|c|c|}
\hline & \multicolumn{2}{|c|}{ Definition 1} & \multicolumn{2}{|c|}{ Definition 2} & \multicolumn{2}{|c|}{ Definition 3} \\
\hline & Coefficient & $\begin{array}{c}\text { Standard } \\
\text { error }\end{array}$ & Coefficient & $\begin{array}{l}\text { Standard } \\
\text { error }\end{array}$ & Coefficient & $\begin{array}{c}\text { Standard } \\
\text { error }\end{array}$ \\
\hline Parent & $-1.61 *$ & 0.92 & $-1.63 *$ & 0.93 & $-1.59 *$ & 0.94 \\
\hline Female & $-1.91^{*}$ & 1.09 & $-2.00 *$ & 1.11 & $-2.01 *$ & 1.11 \\
\hline HS Grad & -0.70 & 1.62 & -0.63 & 1.67 & -0.66 & 1.67 \\
\hline Some college & -1.54 & 2.20 & -1.54 & 2.26 & -1.54 & 2.26 \\
\hline College Grad & $-4.84 *$ & 2.54 & $-4.89 *$ & 2.59 & $-4.83^{*}$ & 2.58 \\
\hline Age & $0.31^{*}$ & 0.19 & $0.34 *$ & 0.19 & $0.33^{*}$ & 0.19 \\
\hline Age Sq. & $-0.0041^{*}$ & 0.0022 & $-0.0044 * *$ & 0.0022 & $-0.0043^{*}$ & 0.0022 \\
\hline Mgr/Prof. ${ }^{a}$ & 0.95 & 1.34 & 0.86 & 1.35 & 0.85 & 1.34 \\
\hline Goods producing & -1.17 & 1.43 & -0.90 & 1.45 & -0.92 & 1.45 \\
\hline Hourlya & -0.24 & 1.22 & -0.01 & 1.24 & 0.00 & 1.24 \\
\hline Hourly missing $\mathrm{a}^{\mathrm{a}}$ & -1.83 & 2.75 & -1.97 & 2.77 & -1.77 & 2.79 \\
\hline Constant & -2.02 & 3.86 & -2.22 & 3.92 & -2.12 & 3.94 \\
\hline
\end{tabular}

a Job characteristics are for the main job, because this information is not available for second jobs in the ATUS.

***Significant at the 1 percent level.

**Significant at the 5 percent level.

*Significant at the 10 percent level.

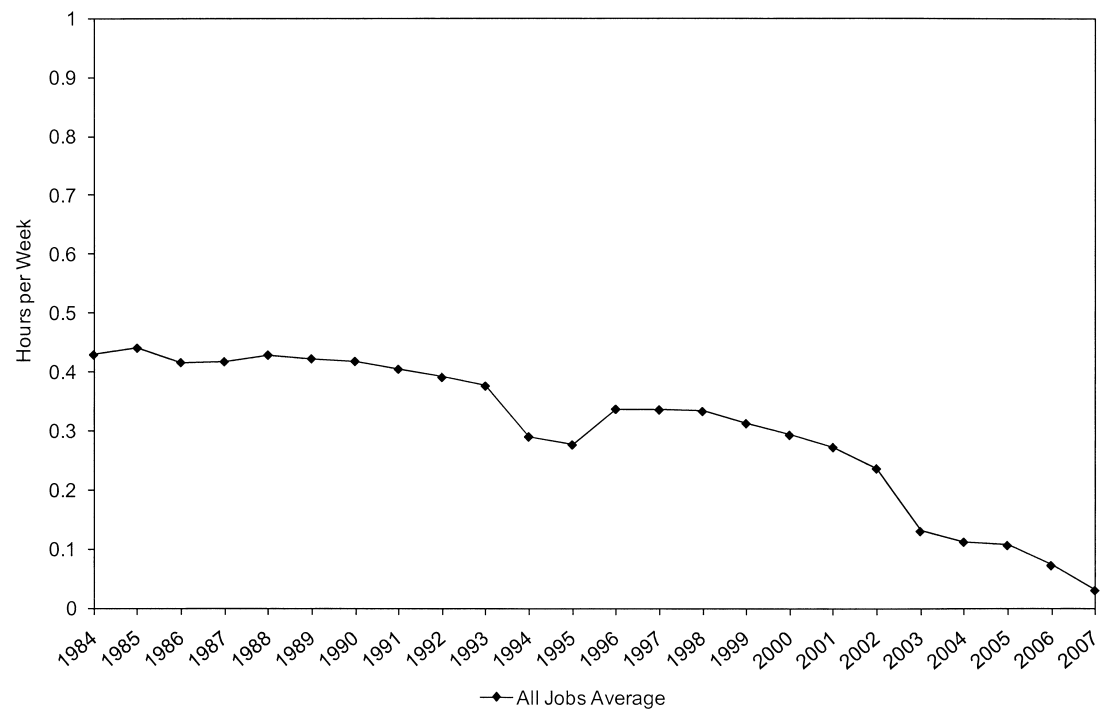

Fig. 9.5 Backcasting of misreporting in CPS 
Bostrom's (1994) finding of increased overreporting. But the 0.4 hour per week change between 1984 and 2007 is small. Thus, misreporting of hours in CPS does not seem to explain much of the CES-CPS divergence.

\subsubsection{The CES Reference Period}

The CES reference period differs from the CPS reference period. As noted earlier, the CPS reference period is the week that includes the 12th of the month, whereas the CES reference period is the pay period that includes the 12 th of the month. Thus, the CES reference period can vary from one week to one month depending on the establishment's length of pay period (LP). Length of pay period matters for two reasons. The first has to do with the distribution of hours worked over the month. A weekly pay period coincides with the CPS reference week, while a biweekly payroll will include the CPS reference week plus either the week before or the week after. ${ }^{23}$ Given that workers work less in non-CPS-reference weeks, estimated average weekly hours will be lower in establishments with biweekly payrolls compared to those with weekly payrolls even if actual hours worked are exactly the same in both establishments.

The second reason has to do with how employees are counted. All employees who worked at the establishment at any time during the pay period are included in the employee count, regardless of how many hours they worked. If total hours are reported correctly, ${ }^{24}$ then reported employment will be too large. To illustrate, suppose a full-time employee quits in the middle of a biweekly pay period and is immediately replaced. Ideally, both employees would be counted as having worked for one-half of the pay period. But both are counted as having worked the entire pay period and average hours for these two employees is twenty per week instead of forty. The longer the pay period and the greater the turnover, the more the employment count will be overstated (and hours understated). ${ }^{25}$

These biases clearly can affect levels, but will have no effect on trends unless there have been changes in the difference in hours worked between CPS reference and nonreference weeks, the fraction of jobs that turnover each month, or the average length of pay period.

There is no direct evidence on how the difference between CPS reference and nonreference week hours has evolved over time. We tabulated ATUS data and found that this difference depends on the industry group (the difference is larger in services-providing industries) and whether workers are paid hourly (the difference is larger for hourly paid workers). This suggests

23. It is also possible that pay periods start in the middle of the week, but this seems to be rare.

24. Establishments are required to keep records of hours worked for hourly paid workers, and it is not unreasonable to suppose that establishments report the standard workweek for salaried positions.

25. See Nardone et al. (2003) for a discussion of how turnover affects the comparison of CES and CPS employment counts. 
that the reference week-nonreference difference may have changed over time through the shift of employment from goods-producing to servicesproviding industries and changes in the fraction paid hourly. ${ }^{26}$

Information on long-term trends in turnover is also rather scant, and many of the data sources that are available have breaks in series that affect comparability over time. However, there is evidence to suggest that turnover has increased since the mid-1970s. Stewart (2007), using data from the March CPS, found that there has been a slight increase in the fraction of workers experiencing a job-to-job transition during the year.

There is very little evidence on how length of pay period in the CES sample has changed since the early 1970s. Microdata are available (though not readily) from 1999 to the present. But the original registry files that contained the LP information were not kept prior to 1999. The only data we have for the pre-1999 period come from a 1981 Records Analysis Survey (RAS) (U.S. Department of Labor 1983). The top panel of table 9.4 shows the establishment-weighted distribution and mean LP for selected years. These distributions are not strictly comparable, but they are the only data that we have available to us. The 1981 data are from the 1981 RAS of respondents in four states (Florida, Massachusetts, Texas, and Utah). The 2002 and 2007 data were tabulated by CES staff on a sample of Touchtone Data Entry (TDE) respondents. It is worth noting that the fraction of respondents reporting by TDE fell between 2002 and 2007 with the increase in Internet reporting. Ideally, we would have employee-weighted distributions, but only establishment-weighted data are available to us.

Table 9.4 indicates that there was virtually no change in mean LP between 1981 and 2002. But between 2002 and 2007, there appears to have been a significant lengthening of pay periods, due mostly to a shift from weekly to biweekly and semimonthly pay periods. The lower portion of table 9.4 shows how LP changed between 2002 and 2007 for individual industry groups. Note that most of the changes are smaller than the aggregate change and that LP has become shorter in some industry groups. Thus, it appears that most of the aggregate change in LP is due to compositional changes rather than within-industry changes.

To determine whether changes in pay-period length (directly and through changes in industry composition), turnover, and the difference in hours worked between reference and nonreference weeks (through changes in industry composition and the fraction paid hourly) could have contributed to the divergence between CES and CPS hours, we simulated their effect on measured CES hours. Our basic strategy was to hold within-group work hours constant, and allow these other factors to change.

26. The fraction paid hourly has increased in both goods-producing and services-providing industries. However, the shift in employment toward services-providing industries (where a smaller fraction of workers are paid hourly) has offset the within-industry changes. 
Table 9.4

Changes in the distribution of length of pay period

\begin{tabular}{|c|c|c|c|c|c|}
\hline & Weekly & Biweekly & Semimonthly & Monthly & Mean LP \\
\hline \multicolumn{6}{|l|}{ Total private } \\
\hline $1981^{\mathrm{a}}$ & 53 & 23 & 20 & 4 & 1.59 \\
\hline 2002 & 48 & 34 & 12 & 5 & 1.63 \\
\hline 2007 & 32 & 46 & 19 & 3 & 1.78 \\
\hline \multicolumn{6}{|l|}{ 2002-Major industry group } \\
\hline Natural resources and mining & 53 & 30 & 11 & 6 & 1.62 \\
\hline Construction & 78 & 14 & 4 & 4 & 1.32 \\
\hline Manufacturing & 64 & 25 & 7 & 3 & 1.42 \\
\hline Wholesale trade & 37 & 39 & 13 & 11 & 1.90 \\
\hline Retail trade & 61 & 27 & 9 & 4 & 1.51 \\
\hline Transportation and warehousing & 61 & 24 & 10 & 5 & 1.52 \\
\hline Utilities & 27 & 53 & 7 & 13 & 2.04 \\
\hline Information & 16 & 61 & 12 & 11 & 2.11 \\
\hline Financial activities & 46 & 27 & 21 & 5 & 1.66 \\
\hline Professional and business services & 40 & 35 & 16 & 8 & 1.78 \\
\hline Private education and health & 17 & 57 & 17 & 9 & 2.06 \\
\hline Leisure and hospitality & 39 & 47 & 10 & 3 & 1.67 \\
\hline Other services & 37 & 41 & 15 & 7 & 1.81 \\
\hline \multicolumn{6}{|l|}{ 2007-Major industry group } \\
\hline Natural resources and mining & 56 & 27 & 15 & 2 & 1.51 \\
\hline Construction & 79 & 14 & 4 & 3 & 1.28 \\
\hline Manufacturing & 64 & 25 & 9 & 2 & 1.42 \\
\hline Wholesale trade & 30 & 45 & 18 & 7 & 1.88 \\
\hline Retail trade & 34 & 52 & 13 & 1 & 1.70 \\
\hline Transportation and warehousing & 49 & 33 & 15 & 3 & 1.60 \\
\hline Utilities & 27 & 62 & 10 & 1 & 1.77 \\
\hline Information & 12 & 75 & 11 & 2 & 1.94 \\
\hline Financial activities & 4 & 54 & 40 & 2 & 2.06 \\
\hline Professional and business services & 37 & 36 & 21 & 6 & 1.80 \\
\hline Private education and health & 13 & 65 & 19 & 3 & 1.97 \\
\hline Leisure and hospitality & 27 & 55 & 16 & 2 & 1.80 \\
\hline Other services & 42 & 35 & 17 & 5 & 1.70 \\
\hline
\end{tabular}

${ }^{a}$ These distributions are establishment weighted. Also, the data in this table are not strictly comparable over time. The 1981 data are from U.S. Department of Labor (1983), and are for Florida, Massachusetts, Texas, and Utah. The data for 2002 and 2007 were compiled by CES staff on Touchtone Data Entry (TDE) respondents. Note that the fraction of respondents that reported via TDE declined over this period with the advent of Internet reporting.

To perform this exercise, we used data from a number of different sources to construct a second simulated average weekly hours measure. For both goods-producing and services-providing industries, we have the following information: the share of employment (from CES), the fraction paid hourly (from CPS), the LP distribution (from table 9.4), hours worked per week by hourly and salaried workers during CPS reference and nonreference weeks (from ATUS). We also use turnover rates from March CPS data, although they are not available by industry group. Equation (3) shows how the simu- 
lated hours data were constructed from these variables (we omitted time subscripts to reduce notational clutter).

$$
\begin{aligned}
\mathrm{AWH}^{i}= & \frac{\left(F_{H}^{i} \times F_{W}^{i} \times H_{H, R}^{i}\right)}{(1+T)} \\
& +\frac{\left(F_{S}^{i} \times F_{W}^{i} \times H_{S, R}^{i}\right)}{(1+T)} \\
& +\frac{\left(F_{H}^{i} \times F_{B}^{i} \times\left[H_{H, R}^{i}+H_{H, N R}^{i}\right] / 2\right)}{(1+2 T)} \\
& +\frac{\left(F_{S}^{i} \times F_{B}^{i} \times\left[H_{S, R}^{i}+H_{S, N R}^{i}\right] / 2\right)}{(1+2 T)} \\
& +\frac{\left(F_{S M}^{i} \times\left[H_{S, R}^{i}+2 H_{S, N R}^{i}\right] / 3\right)}{(1+3 T)} .
\end{aligned}
$$

In equation (3), $F_{H}^{i}$ and $F_{S}^{i}$ are the fractions of workers paid hourly and salaried in industry $i\left(F_{H}^{i}+F_{S}^{i}=1\right) ; F_{W}^{i}, F_{B}^{i}$, and $F_{S M}^{i}$ are the fractions of workers paid weekly, biweekly, and semimonthly or monthly $\left(F_{W}^{i}+F_{B}^{i}+F_{S M}^{i}=1\right) ;{ }^{27}$ $H_{H, R}^{i}, H_{H, N R}^{i}, H_{S, R}^{i}, H_{S, N R}^{i}$ are hours worked per week by hourly/salaried (H,S) workers during CPS reference/nonreference (R, NR) weeks; and $T$ is the weekly turnover rate. We use actual values for each year for $T$ and the $F$ s, while holding the $H$ s constant. Overall simulated average weekly hours in year $t$ are equal to: $H_{t}^{S I M}=F_{t}^{g} \times H_{t}^{g}+F_{t}^{s} \times H_{t}^{s}$, where the superscripts refer to goods-producing $(g)$ and services-providing $(s)$ industries. The adjustment to actual CES hours is equal to the cumulative decline in hours of this simulated hours series. Thus, adjusted CES hours in year $t$ equal: $\tilde{H}_{t}^{C E S}=$ $H_{t}^{C E S}-\left(H_{t}^{S I M}-H_{1973}^{S I M}\right)$, where $H_{t}^{C E S}$ is actual CES hours in year $t$. This series shows what actual CES hours would have been were it not for the interaction of changes in turnover, industry composition, and the fraction paid hourly with changes in the CES reference period.

Before turning to the results, we provide a more complete description of the data we used and how we constructed the variables. The fractions of workers who are paid weekly, biweekly, or semimonthly and monthly were generated using the LP distributions by industry in table 9.4 weighted by the share of CES employment in those industries. Given the small change in the LP distribution between 1981 and 2002, we assumed that the LP distribution was constant between 1973 and 2002 and that the fraction in each LP category changed linearly between 2002 and 2007.

Data on the fraction of workers who are hourly/salaried comes from the

27. We grouped semimonthly and monthly payrolls together and assumed that all of these workers are salaried. This is a reasonable assumption, because semimonthly and monthly payrolls make it more difficult to compute overtime pay for hourly paid workers. Thus, it seems likely that establishments employing hourly workers would opt for weekly or biweekly payrolls. 
1979 to 2007 CPS ORG files and the 1973 to 1979 May CPS files. When hourly/salaried status was missing, it was imputed as described earlier.

Data on hours worked during CPS reference and nonreference weeks are available from the ATUS. But to prevent shifts in employment from highhour goods-producing industries to low-hour services-providing industries from driving our results, we assumed that hours worked during the CPS reference week were the same in both goods-producing and services-providing industries. We further assumed that salaried workers were paid for the same number of hours in CPS reference and nonreference weeks. Specifically, we assigned: $H_{H, R}^{g}=H_{H, R}^{s}=H_{S, R}^{g}=H_{S, R}^{s}=H_{S, N R}^{s}=H_{S, N R}^{g}=37, H_{H, N R}^{g}=$ $36.1, H_{H, N R}^{s}=34.3$. Thus, the shift in employment from goods-producing to services-providing industries affects the overall average weekly hour measure through the lengthening of pay periods and the larger differential between CPS reference and nonreference weeks in services-providing industries.

For the turnover rates, we would ideally like to have had monthly data by industry. Unfortunately, these data are not available in the CPS before 1994. Instead, we use job-to-job transition rates from Stewart (2007) that were generated using March CPS data. The rates are computed on an annual basis and measure the fraction of people who experienced a job-to-job transition during the year. The annual rates tend to lead to an overstatement of turnover, while using persons rather than jobs in calculating turnover works in the opposite direction. We adjusted the annual number so that the monthly number is about the same as in Fallick and Fleischman (2004). ${ }^{28}$ Thus, the transition rates from the March CPS contribute trend and cyclical variation, but not the level. Unfortunately, it is not possible to generate separate transition rates for goods-producing and services-providing industries. Turnover rates are available from the March CPS from 1975 to 2002 (see Stewart 2007). For 1973 to 1974, we assumed that turnover rates were about the same as for 1975 ( 8 percent), and that turnover rates started increasing in 2003 (from 10.5 percent in 2002 to 11 percent in 2003, and to 12 percent in 2004 to 2007).

Figure 9.6 shows the actual CES and the adjusted CES hours series. The adjusted series lies above the actual series indicating that measured hours would have been higher were it not for the increase in the length of the average CES reference period and its interaction with other changes that occurred between 1973 and 2007. The effect is small, about 0.5 hours per week in 2007, but not trivial. Turnover seems to have a relatively large effect on the difference between the adjusted and actual CES series. The difference is larger in expansion years, when there are more job-to-job transitions, and the increasing difference after 1982 coincides with an increase in the job-tojob transition rate.

Given that we do not know how the LP distribution has changed over time, we computed an upper bound on the effect by assuming that all estab-

28. Specifically, we divided the annual rate by two. 


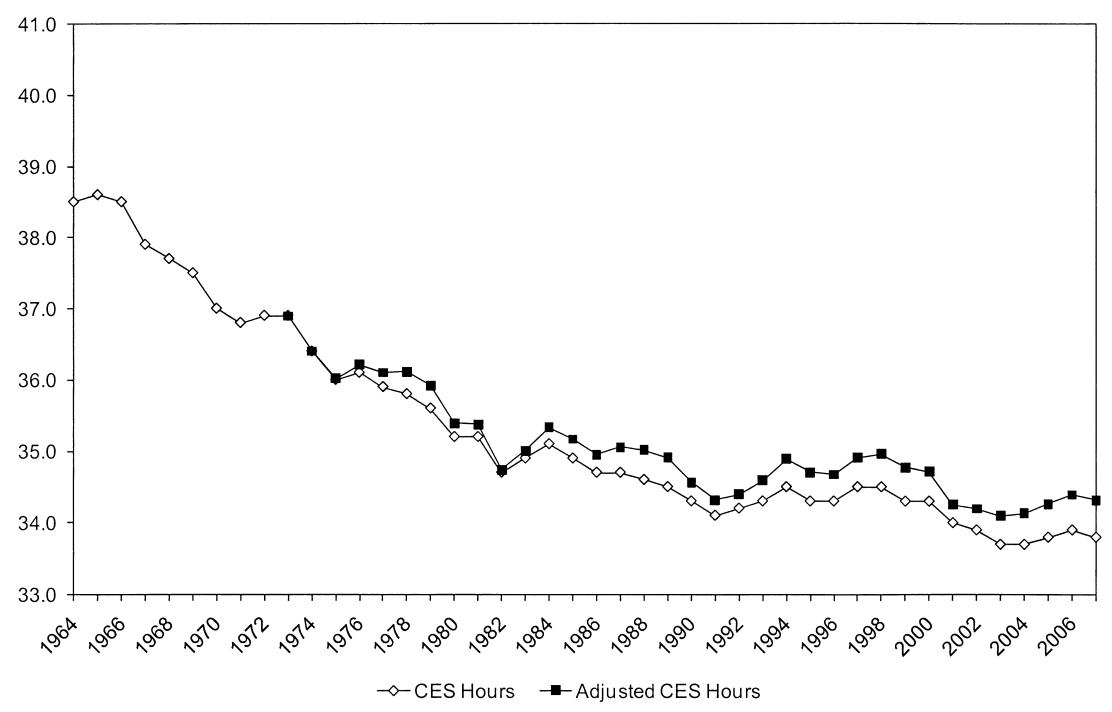

Fig. 9.6 Length-of-pay-period simulation

lishments paid their workers weekly in 1973, and allowed the fraction paying workers biweekly, semimonthly, and monthly to increase gradually to the levels observed in 2002. Between 2002 and 2007, we made the same assumptions about the LP distribution as before. The upper bound is about 0.9 hour per week in 2007, which, given our extreme assumptions, is still rather small.

Thus, the variable reference period in CES combined with other changes appears to have imparted a small downward trend to the CES hours series. However, the effect is small and does not appear to be a major contributor to the divergence of CES and CPS hours. Still, it is worth keeping in mind that this steeper downward trend in CES hours is the result of the interaction of changes in the real economy, with a seemingly innocuous feature of how the CES collects employment and hours data.

\subsection{Discussion}

The goal of our study was to reconcile the large differences, both in level and trend, between the two main sources of hours data published by the BLS - the CES and the CPS. We made some progress. Simulating the CES hours series using CPS data, we found that much of the difference in levels between the two series can be explained by differences in the workers covered (all private nonagricultural workers versus production and nonsupervisory workers), differences in the way average weekly hours are computed in the two surveys (person-based in the CPS and job-based in the CES), and differences in the hours concept (hours worked in CPS versus hours paid in 
CES). But the simulated CES series did not replicate the downward trend in the actual CES data. All of the adjustments to the CPS data resulted in parallel shifts in the series, with virtually no effect on trend. In 2007, the last year of our data, the difference between the actual and simulated CES series in figure 9.4 was 1.6 hours after making the hours worked/hours paid adjustment. It is worth noting that this last adjustment creates a divergence prior to the early 1980 s.

We also considered whether features of the CES data collection could have contributed to the divergence. In particular, we examined the interaction of the increasing average pay period length with other changes such as changes in industry composition and the turnover rate. We found that these factors explained only part of the divergence -0.5 hours per week of the 1.6 hour difference in 2007.

The hypothesis that errors in reporting hours in CPS account for the discrepancy is not supported, as a comparison with the time-diary data from ATUS shows no major differences in hours worked between the surveys for CES jobs. Using the ATUS to generate predicted changes in reporting based on demographic and job characteristics has only a small effect on reconciling trends in the CPS and CES, similar to the changes in reference period.

The end result of our analyses is that we were only partially able to reconcile the differences between the CES and CPS weekly hours series. Differences in coverage and concepts explain the differences in levels, but do not explain the differences in trends. We would like to point future researchers of this topic to avenues that we were unable to fully pursue, but that might bear fruit.

The CES recently started collecting and publishing payroll and hours data for all employees. As of this writing, these are available from March 2006 through November 2007. For this time period, we computed simulated all-employee CES hours using CPS data, making adjustments for multiple jobholding and the difference in concept (hours worked versus hours paid) as described before, and compared them to actual CES all-employee hours. The difference between the two series is 1.8 hours, which is larger than the 1.5 hour difference between the actual CES production/nonsupervisory worker and the MJ \& HPA hours series. Thus, using all-employee hours data does not appear to narrow the difference between CES and CPS hours. Moreover, it also suggests that the residual differences, after all adjustments have been made, between the actual CES and the MJ \& HPA series are real and not an artifact of how we simulated the CES production/nonsupervisory sample in the CPS. In any case, further analysis is warranted as more all-employee hours data become available from the CES.

Another avenue worth exploring is the role of individual industries. Kirkland (2000) argues that much of the decline in CES hours is due to retail trade and services. These are low-hour industries that saw a decline in weekly hours and a large increase in employment. Of course, what matters for our 


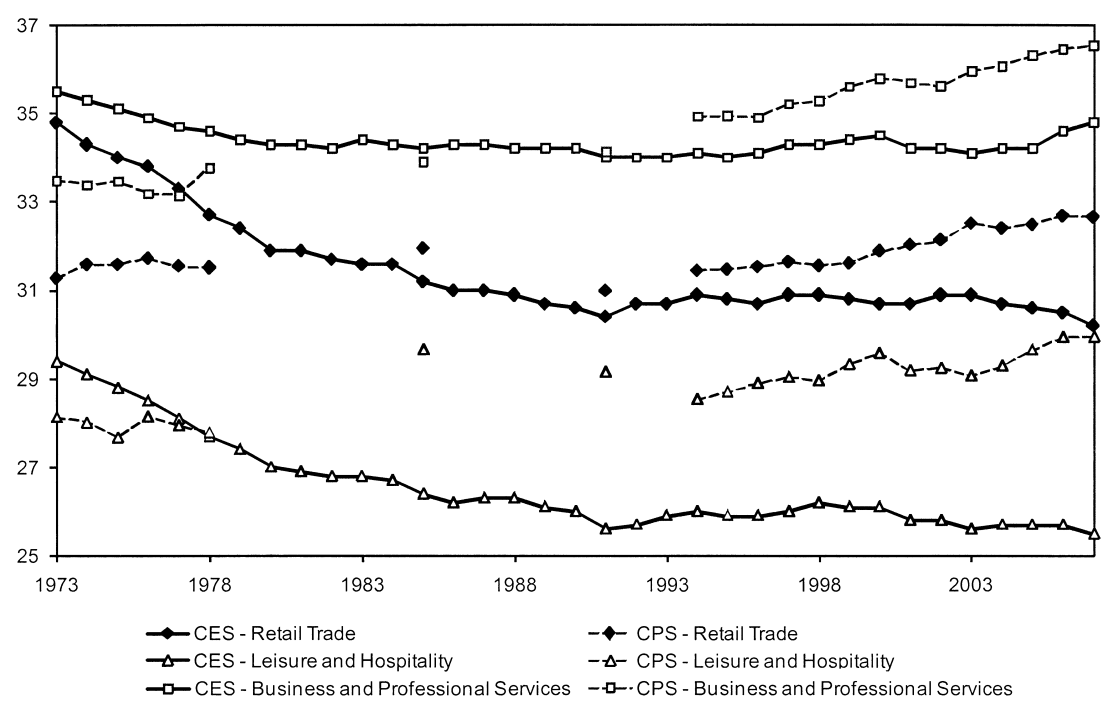

Fig. 9.7 CES and CPS average weekly hours in retail trade, business and professional services, and leisure and hospitality

question is whether these two trends were differentially picked up in the CES and the CPS.

We made an industry-by-industry comparison of CES and CPS hours, and found that three industries - Retail Trade, Leisure and Hospitality, and Business and Professional Services - accounted for most of the difference between the two series. Figure 9.7 shows that there are large differences between the actual CES and the MJ \& HPA simulated CES hours for these three industries. Between 1973 and the early 1980s there were large declines in actual CES hours in Retail Trade and Leisure and Hospitality, and, to a lesser extent, Business and Professional Services. At the same time, their MJ \& HPA counterparts remained approximately constant. In later years, the three actual CES series declined or remained fairly constant, while the three MJ \& HPA series increased.

To investigate how the trends in these three industries affected the overall CES-CPS comparison, we performed a counterfactual experiment. Figure 9.8 shows actual CES hours and MJ \& HPA hours. These were computed as a weighted mean of hours in each industry, where the weights are industry employment shares. Our CF1 counterfactual series uses CES employment shares with CPS hours, while CF2 uses CPS employment shares with CES hours. Comparing the two counterfactual hours series to the two original series shows that it is differences in hours, not employment shares, that is driving the divergence of CPS and CES hours series. ${ }^{29}$ In figure 9.9, we modified

29. The 2002 to 2003 divergence of the counterfactual series from the actual series is likely due to the change in industry codes that occurred at that time. 


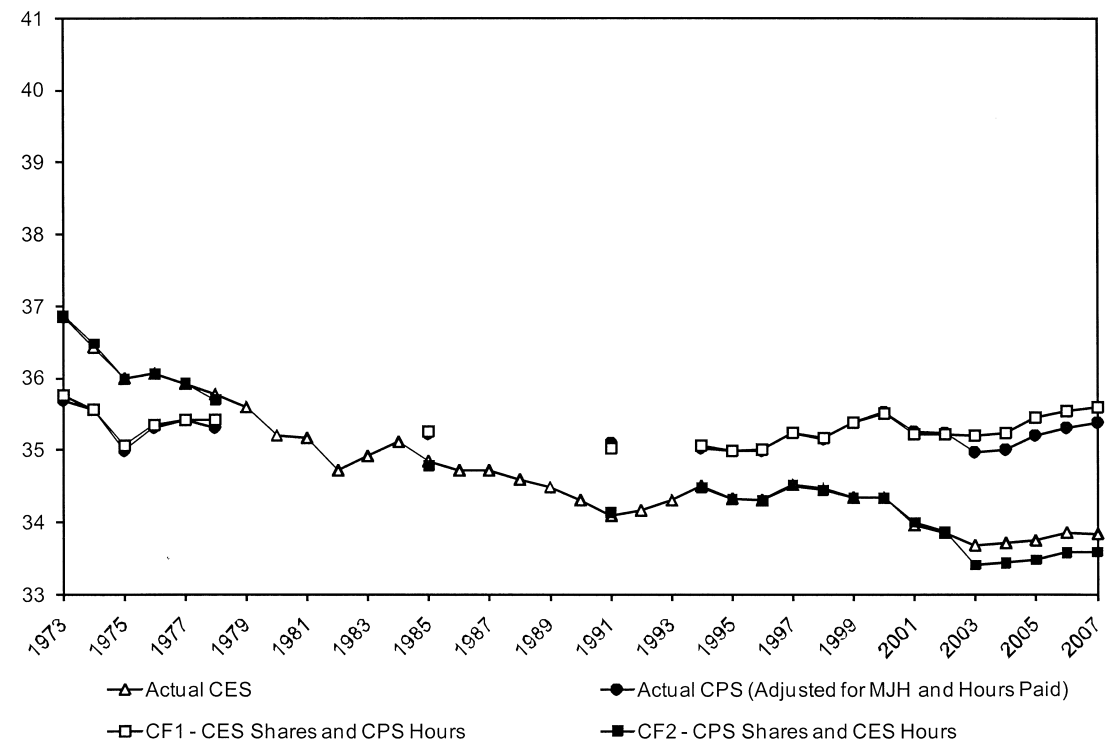

Fig. 9.8 Actual and counterfactual estimates of hours worked per week

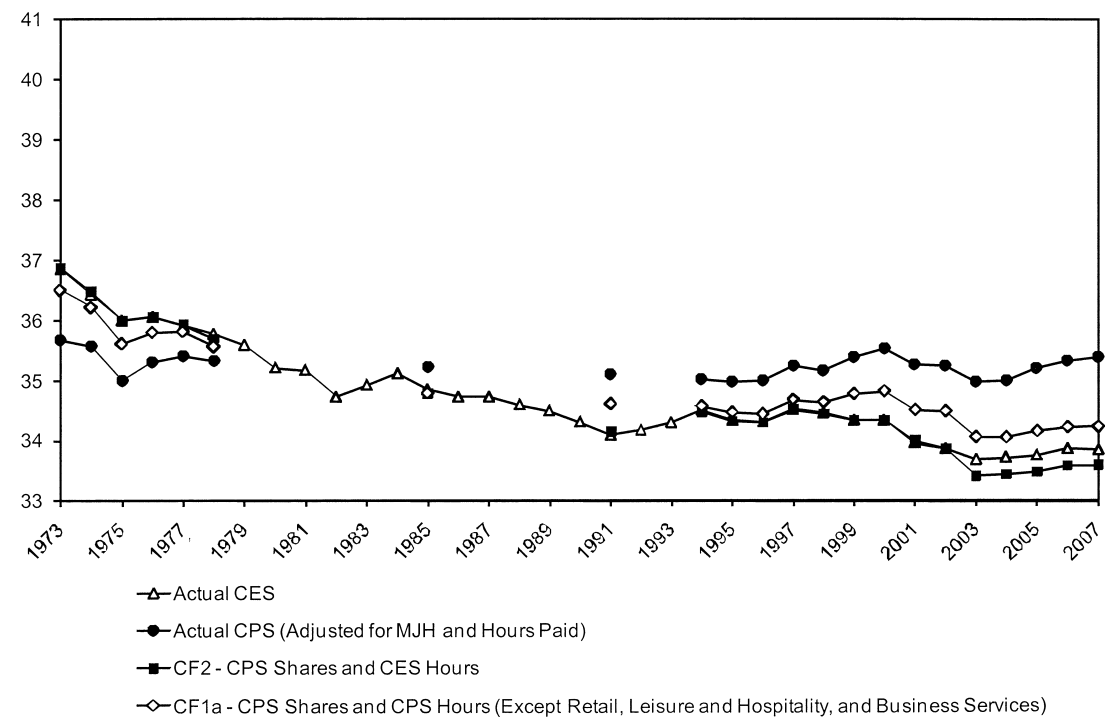

Fig. 9.9 Actual and modified counterfactual estimates of hours worked per week 
CF1 so that CES hours are used for Retail Trade, Leisure and Hospitality, and Business and Professional Services; and CPS hours are used for all other industries. The CF1a series comes much closer, compared to the CF1 series, to replicating the actual CES series in both level and trend. Averaging over all years for which we have data, these three industries explain about two-thirds of the overall difference between the actual CES and MJ \& HPA hours series. In 2007 the difference between the CF1a series and the actual CES is only 0.4 of an hour per week, compared to the 1.5 hour difference between the actual CES and MJ \& HPA hours series. Thus, it appears that it is these industries that contributed the most to the downward trend in actual CES hours. We do not know why these three industries contributed so much to the CES-CPS divergence, but it seems that any further investigation should start there.

\section{References}

Abraham, K. G., J. R. Spletzer, and J. C. Stewart. 1998. Divergent trends in alternative wage series. In Labor statistics measurement issues, NBER Studies in Income and Wealth, vol. 60, ed. J. Haltiwanger, M. E. Manser, and R. Topel, 293-324. Chicago: University of Chicago Press.

. 1999. Why do different wage series tell different stories? American Economic Review Papers and Proceedings 89 (2): 34-9.

Bureau of Labor Statistics 2009. American Time Use Survey User's Guide. Available at: http://www.bls.gov/tus/atususerguide.pdf.

Eldridge, L. P., M. E. Manser, and P. F. Otto. 2004. Hours data and their impact on measures of productivity change. Monthly Labor Review 127 (4): 9-28.

Fallick, B. C., and C. A. Fleischman. 2004. Employer-to-employer flows in the U.S. labor market: The complete picture of gross worker flows. Federal Reserve Board Economics and Finance Discussion Series 2004-34.

Frazis, H., and J. Stewart. 2004. What can time-use data tell us about hours of work? Monthly Labor Review 127 (12): 3-9.

2007. Where does the time go? Concepts and measurement in the American Time Use Survey. In Hard to measure goods and services: Essays in memory of Zvi Griliches, ed. E. Berndt and C. Hulten, 73-97. NBER Studies in Income and Wealth, vol. 67. Chicago: University of Chicago Press.

Hamermesh, D. 1990. Shirking or productive schmoozing: Wages and the allocation of time at work. Industrial and Labor Relations Review 43 (3): 121S-33S.

Hamermesh, D. S., H. Frazis, and J. Stewart. 2005. Data watch-the American Time Use Survey. Journal of Economic Perspectives 19 (1): 221-32.

Kirkland, K. 2000. On the decline in average weekly hours worked. Monthly Labor Review 123 (7): 26-31.

Kuhn, P., and F. Lozano. 2008. The expanding workweek? Understanding trends in long work hours among U.S. men, 1979-2006. Journal of Labor Economics 26 (2): 311-43.

Mellow, W., and H. Sider. 1983. Accuracy of response in labor market surveys: Evidence and implications. Journal of Labor Economics 1 (4): 331-44.

Nardone, T., M. Bowler, J. Kropf, K. Kirkland, and S. Wetrogan. 2003. Examining 
the discrepancy in employment growth between the CPS and the CES. Paper presented at the meeting of the Federal Economic Statistics Advisory Committee. October.

Robinson, J. and A. Bostrom. 1994. The overestimated workweek? What time diary measures suggest. Monthly Labor Review 117 (1): 11-23.

Rodgers, W. L., C. Brown, and G. J. Duncan. 1993. Errors in survey reports of earnings, hours worked, and hourly wages. Journal of the American Statistical Association 22 (424): 1208-18.

Stewart, J. 2007. Using March CPS data to analyze labor market transitions. Journal of Economic and Social Measurement 32 (2-3): 177-97.

Sundstrom, W. 1999. The overworked American or the overestimated workweek? Trends and biases in recent estimates of weekly work hours in the United States. Santa Clara University. Unpublished Manuscript.

U.S. Department of Labor, Bureau of Labor Statistics. 1983. Employer Records Analysis Survey of 1981. Final Report.

Williams, R. D. 2004. Investigating hours worked measures. Labour Market Trends 112 (2): 71-79.

\section{Comment Charles Brown}

Harley Frazis and Jay Stewart have written a very careful chapter on an important topic. Trends in hours worked are a direct object of interest (how much of the improvement in living standards generated by productivity growth is being taken as leisure?) and are an essential component in computing trends in hourly wages and productivity growth. Two major data series track hours worked over time- the household-based Current Population Survey (CPS) and the employer-reported Current Employment Statistics (CES) survey. The CPS workweeks are higher, and show little of the trend decline that one sees in the CES. This substantial difference is cause for concern. In the decade since Abraham, Spletzer, and Stewart first explored the question, the simple addition of ten more years of data has done nothing to resolve it. Frazis and Stewart's contribution is an admirable blend of imagination, care, and their intimate knowledge of (and access to) a wide range of data. They make some progress, particularly with respect to differences in average hours worked over the period studied. They are less successful in accounting for divergent time patterns. Their clear-eyed assessment of what they have and have not done will make this chapter the obvious starting point as others bring further ideas to the discussion.

In reading the chapter, I found it helpful to divide it into three sections. First, CPS and CES differ in the unit for which the hours measure is being

Charles Brown is a research professor in the Survey Research Center and professor of economics at the University of Michigan, and a research associate of the National Bureau of Economic Research. 